\title{
Missing links in understanding redox signaling via thiol/disulfide modulation: how is glutathione oxidized in plants?
}

\author{
Marie-Sylviane Rahantaniaina ${ }^{1,2}$, Andrée Tuzet ${ }^{2}$, Amna Mhamdi ${ }^{1}$ and Graham Noctor ${ }^{1 *}$ \\ ${ }_{1}$ Institut de Biologie des Plantes, Université Paris-Sud, Orsay, France \\ 2 Institut National de Recherche Agronomique, UMR Environnement et Grandes Cultures, Thiverval-Grignon, France
}

Edited by:

Jean-Philippe Reichheld, CNRS,

France

Reviewed by:

Christine H. Foyer, University of

Leeds, UK

Stéphane D. Lemaire, CNRS - Univ

Pierre et Marie Curie, France

\section{*Correspondence:}

Graham Noctor, Institut de Biologie des Plantes, Université de Paris sud, Bâtiment 630, 91405 Orsay, France e-mail: graham.noctor@u-psud.fr
Glutathione is a small redox-active molecule existing in two main stable forms: the thiol (GSH) and the disulphide (GSSG). In plants growing in optimal conditions, the GSH:GSSG ratio is high in most cell compartments. Challenging environmental conditions are known to alter this ratio, notably by inducing the accumulation of GSSG, an effect that may be influential in the perception or transduction of stress signals. Despite the potential importance of glutathione status in redox signaling, the reactions responsible for the oxidation of GSH to GSSG have not been clearly identified. Most attention has focused on the ascorbate-glutathione pathway, but several other candidate pathways may couple the availability of oxidants such as $\mathrm{H}_{2} \mathrm{O}_{2}$ to changes in glutathione and thus impact on signaling pathways through regulation of protein thiol-disulfide status. We provide an overview of the main candidate pathways and discuss the available biochemical, transcriptomic, and genetic evidence relating to each. Our analysis emphasizes how much is still to be elucidated on this question, which is likely important for a full understanding of how stress-related redox regulation might impinge on phytohormone-related and other signaling pathways in plants.

Keywords: oxidative stress, hydrogen peroxide, dehydroascorbate, glutathione $S$-transferase, glutaredoxin

\section{INTRODUCTION}

Arabidopsis cannot develop past the embryonic stage without glutathione (Cairns et al., 2006), a multifunctional tripeptide thiol found in the cells of most organisms. Although this small molecule has diverse roles in defense and metabolism, a key function is in redox homeostasis (Foyer and Noctor, 2011). This protective role notably involves acting in the metabolism of oxidants such as reactive oxygen species (ROS) and buffering protein thiol groups against excessive oxidation. Like most other biological roles of glutathione, these functions depend on the redox-active cysteine residue.

While the cysteine sulphur can exist in several redox states, the key stable forms are the thiol found in reduced glutathione (GSH) and the disulphide found in GSSG. Other factors remaining constant, the concentrations of the two forms modulate the effective redox potential of the couple according to the relationship $[\mathrm{GSH}]^{2} /[\mathrm{GSSG}]$ (Meyer, 2008). When plants are growing in unchallenging conditions, in which GSHoxidizing compounds are kept relatively low by cellular antioxidant systems, the glutathione redox potential in subcellular

${ }^{\mathrm{a}} \mathrm{GSH}$ and GSSG are used here to refer specifically to the thiol and disulphide forms of glutathione. Where both forms may be referred to, "glutathione" is used.

${ }^{\mathrm{b}} \mathrm{GPX}$ is used to refer to a specific family of genes encoding enzymes that may catalyse only low rates of this activity in vivo. To avoid confusion, the biochemical activity of glutathione peroxidation (e.g., catalysed by some glutathione $S$-transferases) is denoted by the abbreviation "GSH peroxidase." compartments such as the cytosol, chloroplast, and mitochondria is maintained at highly reducing values. Redox-sensitive green fluorescent proteins (roGFP) have been developed as in vivo probes for cell thiol-disulfide status. Although it cannot be completely excluded that other thiols may influence their status in vivo, the in vitro specificity of roGFP oxidoreduction suggests that they report mainly on the glutathione redox potential (Meyer et al., 2007). Analyses using these probes have measured redox potentials in the cytosol, chloroplasts and mitochondria that are close to $-320 \mathrm{mV}$, the midpoint potential of NADPH (Meyer et al., 2007; Schwarzländer et al., 2008; Jubany-Mari et al., 2010). If these values faithfully reflect the glutathione redox potential, they imply that the GSH:GSSG ratio is well over 1000. Thus, while total glutathione concentrations are typically in the $1-10 \mathrm{mM}$ range (Queval et al., 2011), GSSG concentrations in unchallenging conditions may be $10^{3}-10^{6}$ times lower in compartments that contain significant activities of GR.

When plants are subject to suboptimal conditions, GSSG can accumulate to higher levels. This phenomenon is observed in extracts of plants exposed to various abiotic and biotic stresses (Edwards et al., 1991; Sen Gupta et al., 1991; Vanacker et al., 2000; Bick et al., 2001; Gomez et al., 2004). Based on studies of plants deficient in enzymes such as ascorbate peroxidase (APX) and catalase (CAT), accumulation of GSSG is quite closely related to the intracellular availability of $\mathrm{H}_{2} \mathrm{O}_{2}$ (Rizhsky et al., 2002; Mhamdi et al., 2010a), which is expected to be enhanced in stress conditions. 
The principal reactions and proteins responsible for reducing GSSG to GSH in plants are relatively well characterized. In Arabidopsis, two genes each encode dual-targeted glutathione reductases (GR), and this is sufficient to explain the presence of GR activity in the chloroplasts, mitochondria, cytosol, and peroxisomes (Chew et al., 2003; Kataya and Reumann, 2010). Given that GR has a $K_{\mathrm{M}}$ value for NADPH below $10 \mu \mathrm{M}$ (Edwards et al., 1990), conversion of GSSG to GSH is unlikely to be limited by reductant. Moreover, loss of function of GR1, encoding the cytosol/peroxisome enzymes, causes only moderate GSSG accumulation in leaf tissue, an observation explained by the existence of an auxiliary GSSG-reducing activity ensured by cytosolic NADPH-thioredoxin (TRX) systems (Marty et al., 2009). However, GR1 becomes more important in oxidative stress conditions (Mhamdi et al., 2010b; Dghim et al., 2013).

In contrast to GSSG reduction, the reactions that are most important in converting GSH to GSSG are less clear and, potentially, more complex. Since GSSG accumulation is not only a useful biochemical marker for oxidative stress in plants, but may also be of functional importance in transmitting signals triggered by increased $\mathrm{H}_{2} \mathrm{O}_{2}$ (Han et al., 2013a,b), the aim of the discussion below is to present an overview of current knowledge on the reactions that could be responsible for this phenomenon.

\section{CANDIDATE PATHWAYS ENZYME-INDEPENDENT OXIDATION}

Because GSH oxidation is strongly dependent on deprotonation to the thiolate form ( $\mathrm{GS}-$ ), electron transfer is $\mathrm{pH}$-dependent. The $\mathrm{pKa}$ of the GSH thiol is about 9.0. Thus, only about $1 \%$ of GSH thiols will be deprotonated at any one moment in the cytosol ( $\mathrm{pH}$ 7.2). This percentage will be even less in more acidic compartments such as the vacuole or apoplast, although GSH concentrations are relatively low at these locations. In the chloroplast, the chemical reactivity of GSH will be favored in the light compared to the dark because photosynthetic electron transport drives alkalinisation of the stroma. Chemical oxidation of GSH can therefore be influenced by physiologically relevant changes in $\mathrm{pH}$. Decreases in proton concentration will also decrease the glutathione redox potential for a given value of $[\mathrm{GSH}]^{2} /[\mathrm{GSSG}]$.

The nucleophilic properties of GS- mean that it can react with a wide spectrum of electrophiles. In some cases, this will not lead to oxidation to GSSG or other disulfide but rather formation of a stable $S$-conjugate with various compounds (Dixon and Edwards, 2010). Such GS-conjugates are generally transported by ATP-dependent pumps (ABCC proteins) to the vacuole, where the constituent amino acids of the glutathione moiety are recycled (Martinoia et al., 1993; Lu et al., 1998; Grzam et al., 2006). Among the molecules able to oxidize GSH to produce GSSG are ROS and dehydroascorbate (DHA), the stable non-radical product of ascorbate oxidation. Rate constants for reactions with some of these compounds are shown in Table 1. Glutathione reacts with singlet oxygen and superoxide at rates similar to other molecules with recognized antioxidant properties, such as ascorbate and phenolic compounds. However, both glutathione and ascorbate react appreciably slower with singlet oxygen than tocopherols and, especially, carotenoids (Table 1). While the reaction between GSH and the hydroxyl radical is very fast, this powerful
Table 1 | Rates of nonenzymatic reactions between glutathione and various oxidants.

\begin{tabular}{|c|c|c|}
\hline Oxidant & Metabolite & $k\left(M^{-1} s^{-1}\right)$ \\
\hline \multirow[t]{4}{*}{ Singlet oxygen } & Glutathione $^{a}$ & $2 \times 10^{6}$ \\
\hline & Ascorbate $^{a}$ & $1 \times 10^{7}$ \\
\hline & $\beta$-Carotene ${ }^{b}$ & $1.4 \times 10^{10}$ \\
\hline & $\alpha$-Tocopherol ${ }^{b}$ & $3 \times 10^{8}$ \\
\hline \multirow[t]{4}{*}{ Superoxide } & Glutathione ${ }^{a}$ & $7 \times 10^{5}$ \\
\hline & Ascorbate ${ }^{a}$ & $2 \times 10^{5}$ \\
\hline & Kaempferolc & $5.5 \times 10^{5}$ \\
\hline & Quercetinc & $0.9 \times 10^{5}$ \\
\hline \multirow[t]{7}{*}{ Hydroxyl radical } & Glutathione $^{f}$ & $8.1 \times 10^{9}$ \\
\hline & Ascorbate $^{f}$ & $1.5 \times 10^{9}$ \\
\hline & Kaempferolc & $4.6 \times 10^{9}$ \\
\hline & Quercetin ${ }^{c}$ & $4.3 \times 10^{9}$ \\
\hline & Glucose $^{f}$ & $4.0 \times 10^{9}$ \\
\hline & Sucrose ${ }^{f}$ & $8.9 \times 10^{9}$ \\
\hline & Galactinol $^{f}$ & $7.8 \times 10^{9}$ \\
\hline \multirow[t]{4}{*}{ Hydrogen peroxide } & Glutathione $^{d}$ & 0.9 \\
\hline & Ascorbate ${ }^{\mathrm{e}}$ & 2 \\
\hline & Cysteine $^{d}$ & 2.9 \\
\hline & Thioredoxin $^{d}$ & 1.1 \\
\hline Dehydroascorbate & Glutathione $^{g}$ & $1 \times 10^{5}$ \\
\hline
\end{tabular}

For comparative purposes, rate constants are also shown for ascorbate and other metabolites.

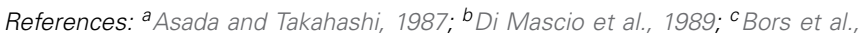
1990; ' Winterbourn, 2013; e Polle, 2001; ${ }^{f}$ Nishizawa et al., 2008; g Hausladen and Kunert, 1990. Values for thioredoxin are for the E.coli protein.

oxidant also reacts rapidly with numerous other metabolites that are present in the cellular environment at higher concentrations than GSH, such as ascorbate and sugars (Table 1). Thus, other compounds might be expected to compete effectively with GSH in the scavenging of both singlet oxygen and the hydroxyl radical. As for other non-enzymatic thiols, and ascorbate, the chemical reaction with $\mathrm{H}_{2} \mathrm{O}_{2}$ is very slow. Superoxide and DHA are therefore the most likely of the molecules shown in Table 1 to contribute to uncatalyzed production of GSSG in vivo. This conclusion receives some support from kinetic modeling studies (Polle, 2001).

\section{THE ASCORBATE-GLUTATHIONE PATHWAY}

The slow chemical reaction of GSH with $\mathrm{H}_{2} \mathrm{O}_{2}$ contrasts with the rapid reaction with DHA (Table 1). This is the key observation underlying the importance ascribed to the close redox coupling of ascorbate and glutathione pools in vivo, which allows glutathione to play an indirect role in $\mathrm{H}_{2} \mathrm{O}_{2}$ reduction as part of a reaction sequence that ultimately depends on electrons derived from $\mathrm{NAD}(\mathrm{P}) \mathrm{H}$ and/or ferredoxin (Figure 1). Thus, APX reduces $\mathrm{H}_{2} \mathrm{O}_{2}$ to water, yielding monodehydroascorbate (MDHA) as an unstable initial product. MDHA that is not rapidly reduced can dismutate to ascorbate and DHA, which can then be reduced by GSH with the concomitant production of GSSG (Figure 1). 


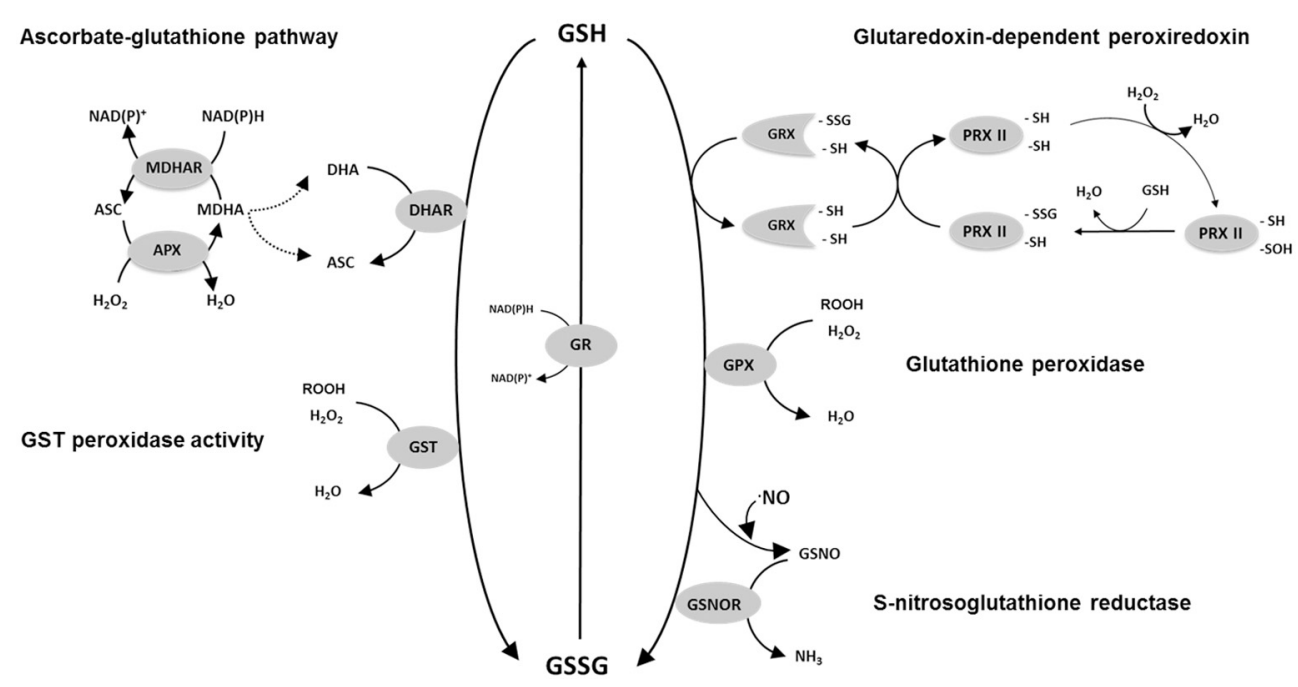

FIGURE 1|Scheme of some of the possible reactions involved in GSH oxidation in plants. Not all possible reactions or reaction mechanisms are shown. For reasons of clarity, stoichiometries are not depicted. For PRXII a proposed regeneration mechanism of PrX IIE using the GSH/Grx system is shown according to Gama et al. (2008). Abbreviations: GSH, reduced glutathione; GSSG, glutathione disulphide; GR, glutathione reductase; DHAR, dehydroascorbate reductase; APX, ascorbate peroxidase; MDHAR, monodehydroascorbate reductase; ASC, ascorbate; DHA dehydroascorbate; MDHA, monodehydroascorbate; $\mathrm{H}_{2} \mathrm{O}_{2}$, hydrogen peroxide; GST, glutathione S-transferase, GRX, glutaredoxin; PRX, peroxiredoxin; -SH, sulfhydryl (thiol) group; -SSG, glutathionylated protein Cys residue; GSNO, S-nitrosoglutathione; GSNOR, GSNO reductase; GPX, glutathione peroxidase.
While GSH can chemically reduce DHA at high rates, the reaction is accelerated significantly by DHA reductases (DHAR; Foyer and Halliwell, 1977). These enzymes have been purified from several species (Hossain and Asada, 1984; Dipierro and Borranccino, 1991; Urano et al., 2000). In Arabidopsis, at least three DHAR genes are expressed. Although they are not able to catalyze glutathione $S$-conjugation reactions at significant rates, they are considered to belong to the glutathione $S$-transferase (GST) superfamily (Dixon and Edwards, 2010). The difference in the activities of DHARs and most classes of GST is explained by the presence of a cysteine in place of serine at the active sites of DHARs (Dixon et al., 2002).

\section{GLUTATHIONE PEROXIDASE (GPX)}

Although GSSG could be generated as a product of GSHdependent DHA reduction, genomics has revealed the complexity of the plant antioxidative system and identified several GSHdependent enzymes that may play more direct roles in peroxide metabolism. GPX has long been known to be a player in $\mathrm{H}_{2} \mathrm{O}_{2}$ metabolism in mammalian cells, but only began to be seriously studied in plants following the description of sequences homologous to the animal enzymes in the 1990s. Described as glutathione hydroperoxidases, the plant GPXs are distinguished from animal GPXs in having an active site cysteine in place of selenocysteine (Eshdat et al., 1997), even though both selenocysteineand cysteine-dependent GPXs are found in unicellular algae such as Chlamydomonas (Dayer et al., 2008). Genome sequencing has shown that plant GPXs are encoded by several genes ( 8 in Arabidopsis). Despite their current nomenclature, several independent studies have shown that the encoded enzymes prefer TRX as reductant and have comparatively low activity against
GSH (Herbette et al., 2002; Iqbal et al., 2006; Navrot et al., 2006). Thus, they might be considered to be TRX-dependent peroxiredoxins, and so not strong candidates to account for GSSG accumulation in vivo. However, they are included in Figure 1 because it cannot as yet be discounted that they make some contribution to the GSH oxidation that occurs during stress.

\section{GLUTATHIONE S-TRANSFERASES (GST)}

The GST superfamily is composed of 55 genes in Arabidopsis, including the DHAR sequences mentioned above (Dixon and Edwards, 2010). As well as the DHARs, the family is divided into several classes (zeta, theta, TCHQD, phi, tau, lambda), with the last three being specific to plants. The most numerous are the phi and tau classes, composed of 13 and 28 genes, respectively (Supplemental Table 1). Proteins that catalyze the classical conjugase reaction using GSH are found in several classes. At least some GSTs can also use GSH to reduce organic hydroperoxides (Cummins et al., 1999; Figure 1). Studies on the Arabidopsis proteins have revealed that several classes of GST include enzymes with both conjugase and peroxidase activities (Dixon et al., 2009; Dixon and Edwards, 2010). Enzymes of the lambda class are unusual in that they do not catalyze conjugase reactions. Like DHARs, they have an active-site cysteine and function as monomers (Dixon et al., 2002). They may generate GSSG by catalyzing the reduction of small molecules or, possibly, the deglutathionylation of protein cysteine residues (Dixon et al., 2002; Dixon and Edwards, 2010).

\section{PEROXIREDOXINS (PRX)}

These enzymes are classed into several types: 2-cys PRX, 1-cys PRX, type II PRX, and PRX Q (Dietz et al., 2002). The first 
to be studied in plants was chloroplastic 2-Cys PRX, which can be regenerated by specific thioredoxins or by an NADPHthioredoxin reductase (Dietz, 2003; Collin et al., 2004; Pulido et al., 2010). However, plants also contain several type II PRX that, once oxidized by peroxides or other compounds, can oxidize glutathione, particularly via glutaredoxins (GRX; Figure 1). Interactions between PRXII and GRX have been studied at the biochemical level in poplar and Arabidopsis (Rouhier et al., 2002; Bréhélin et al., 2003; Couturier et al., 2011; Riondet et al., 2012). PRXII are encoded by five expressed genes in Arabidopsis. While information is emerging, the identification of the GRXs that couple their re-reduction to GSH oxidation in vivo remains incomplete (Rouhier, 2010).

\section{OTHER POSSIBILITIES}

The reactions outlined above are not intended to be exhaustive. Numerous other routes could allow oxidation of GSH to GSSG. A comprehensive treatment of all of these is beyond the scope of this discussion. Among other possibilities of note is the reaction catalyzed by $S$-nitrosoglutathione (GSNO) reductase (Figure 1), which can produce GSSG from GSH and GSNO. Although this enzyme is receiving considerable attention for its role in various physiological functions (Sakamoto et al., 2002; Díaz et al., 2003; Barroso et al., 2006; Kwon et al., 2012), its capacity relative to enzymes such as DHAR is unclear. Adenosine phosphosulfate reductase (APR), a key chloroplastic enzyme in sulphate reduction, uses GSH as electron donor (Bick et al., 1998). The capacity of this enzyme is relatively low, although the activity may be stimulated by enhanced expression and post-translational activation in oxidative stress conditions, notably to produce cysteine for glutathione synthesis (Bick et al., 2001; Queval et al., 2009).

At least one type of plant methionine sulphoxide reductase activity may be coupled to GSH oxidation via glutathione-linked GRX (Tarrago et al., 2009). This enzyme regulates the oxidation state of protein methionine residues but based on its turnover rates (Tarrago et al., 2009), it is unlikely to make an appreciable contribution to increases in GSSG during oxidative stress. One interesting mechanism that could potentially contribute has been described as "proteome-dependent glutathione peroxidase" (Zaffagnini et al., 2012). This process, which could be stimulated under conditions of stress, envisages a chloroplastic sequence of reactions involving $\mathrm{H}_{2} \mathrm{O}_{2}$-triggered $S$-glutathionylation of diverse available protein cysteine residues, followed by regeneration of the free cysteines by glutathione-dependent GRX (Zaffagnini et al., 2012). The net result would be reduction of $\mathrm{H}_{2} \mathrm{O}_{2}$ to two water molecules with oxidation of $2 \mathrm{GSH}$ to GSSG, i.e., a GSH peroxidase reaction. Such a sequence may share mechanistic features with the PRXII-GRX pathway shown in Figure 1, a principal difference being that $\mathrm{H}_{2} \mathrm{O}_{2}$ would not react with a specific catalytic cysteine but rather in a more general way with free and reactive chloroplast protein cysteines. As yet, the physiological significance of this process is difficult to evaluate, although it has been noted that the abundance of potentially reactive cysteines in chloroplast proteins is far from negligible (Zaffagnini et al., 2012).

\section{SUBCELLULAR COMPARTMENTATION}

Supplemental Table 1 presents a list of Arabidopsis genes involved in the pathways shown in Figure 1. Given the relative concentrations of different ROS, the battery of $\mathrm{H}_{2} \mathrm{O}_{2}$ metabolizing enzymes potentially linked to glutathione, and the marked changes in glutathione status when other $\mathrm{H}_{2} \mathrm{O}_{2}$ metabolizing enzymes such as catalase are down-regulated, the main focus of the following discussion concerns the enzymes that could be important in linking $\mathrm{H}_{2} \mathrm{O}_{2}$ or related peroxides to GSH oxidation to GSSG. Based on the above discussion, we suggest that the major candidates to perform this function are (1) DHARs, (2) GSTs, and (3) GRX-PRXII. The subcellular compartmentation of Arabidopsis proteins within these families is summarized in Figure 2.

While DHAR1 has been localized to the peroxisomes, DHAR2 is cytosolic and DHAR3 encodes a dual-addressed chloroplast/mitochondrial enzyme (Figure 2). These three genes are therefore sufficient to explain the presence of the ascorbateglutathione cycle in these compartments (Foyer and Halliwell, 1977; Jiménez et al., 1997). Three type II PRX (PRXIIB, C, D) are found in the cytosol, with PRXIIE and PRXIIF located in the chloroplast and mitochondrion, respectively (Figure 2; Rouhier and Jacquot, 2005; Tripathi et al., 2009).

Many GSTs are located in the cytosol, but several of these have also been detected in other compartments such as the chloroplast (Figure 2; Supplemental Table 1). The only types of GST that are not thought to be found in the cytosol are the theta class, encoded by three genes that direct the proteins to the peroxisome (Dixon et al., 2009). The GFP-fusion proteins of GSTU12 and GSTT3L were found to be localized in the nucleus (Dixon et al., 2009).

\section{EVIDENCE FOR THE IMPORTANCE OF THE DIFFERENT PATHWAYS \\ BIOCHEMICAL DATA \\ DHA as oxidant}

On the basis of modeling of ROS metabolism in the chloroplast, it was suggested that the ascorbate pool could operate largely

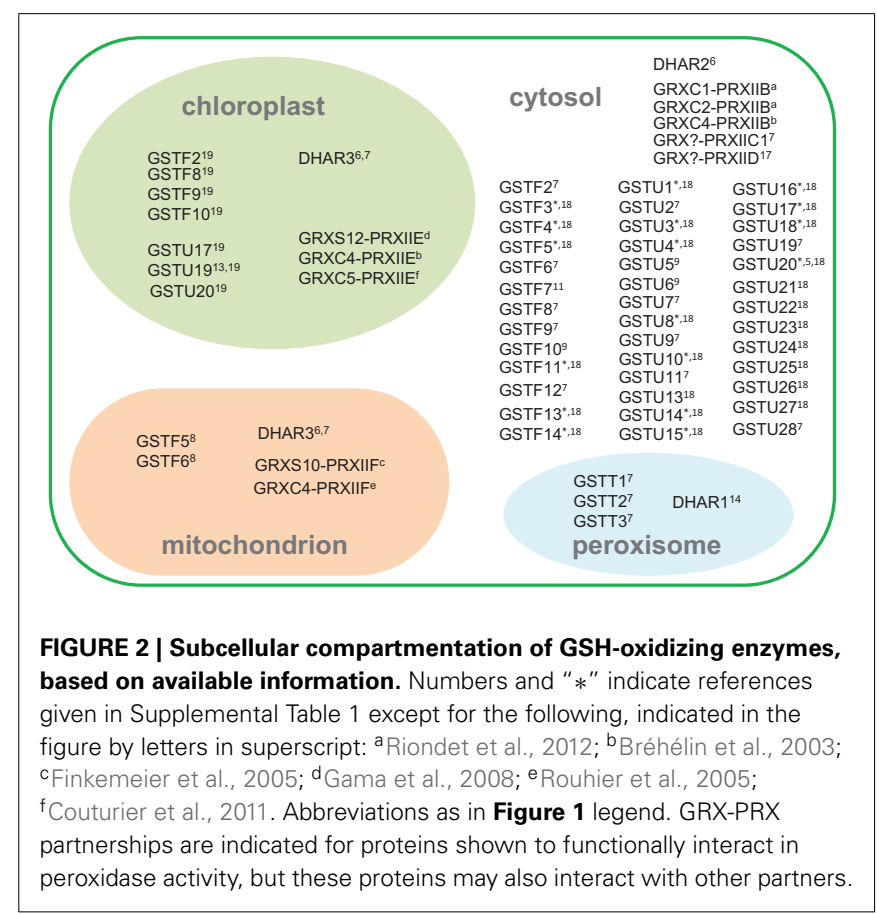


independently of glutathione because most of the MDHA produced would be efficiently reduced to ascorbate, entailing the formation of little DHA (Polle, 2001). It was concluded that the chemical reaction with GSH would suffice to reduce the small amounts of DHA produced (Polle, 2001). It is possible that this situation is specific to the illuminated chloroplast.

Both the chemical and enzyme-dependent reduction of DHA can be easily detected in vitro by following the GSHdependent production of ascorbate in the absence and presence of crude protein extract. The total enzyme-dependent leaf activity that can be measured in standard assay conditions is around $0.2-0.5 \mu \mathrm{mol} . \mathrm{mg}^{-1}$ total protein. $\mathrm{min}^{-1}$, which is typically about twice the total leaf GR activity but somewhat lower than extractable APX (e.g., Sen Gupta et al., 1993; Mhamdi et al., 2010b).

A protein purified from spinach by classical biochemical procedures, considered to be a cytosolic DHAR, had $K_{\mathrm{M}}$ values of $2.5 \mathrm{mM}$ and $70 \mu \mathrm{M}$ for GSH and DHA, respectively (Hossain and Asada, 1984). Analysis of a purified chloroplast protein produced similar values, although with a somewhat higher affinity for GSH (Shimaoka et al., 2000). Subsequent studies of recombinant DHARs from Arabidopsis, poplar, and rice produced similar maximal activities and $K_{\mathrm{M}}$ values to these preparations, although the organellar forms in Arabidopsis have a significantly lower affinity for GSH (Table 2). With the exception of values reported for the Arabidopsis enzymes, the $K_{\mathrm{M}}$ values for GSH are below or close to in vivo concentrations (Queval et al., 2011). Much of the DHA that can be measured in unstressed plant tissues is probably apoplastic (Foyer and Noctor, 2011) and concentrations are probably low in compartments that contain GSH (Polle, 2001). If so, oxidative stress-induced changes in DHA could be a major factor contributing to accelerated activity in vivo, at least in some compartments. Under conditions favoring accumulation of $\mathrm{H}_{2} \mathrm{O}_{2}$, a second factor that could come into play is increases in DHAR abundance. The expression of some DHAR genes is increased by oxidative stress (discussed further in the next section).

\section{GST activities}

Although they have hydroperoxide activity, GSTs generally use $\mathrm{H}_{2} \mathrm{O}_{2}$ only at low rates (Mannervik, 1985). The physiological oxidants used by the different GSTs in plants remain in many cases to be identified, and studies of their biochemical activities frequently use the artificial substrate, cumene hydroperoxide. Specific GSTs have been purified from several species and their activities as conjugases or peroxidases compared (DeRidder et al., 2002; Cummins et al., 2003; Park et al., 2005; Nutricati et al., 2006; Yang et al., 2009). Such studies reveal that the $K_{M}$ values of GSTs for GSH in conjugase reactions are generally below $2 \mathrm{mM}$. Some studies have compared the peroxidatic competence of several GSTs from the same species (Wagner et al., 2002; Dixon et al., 2009). Most notably, the detailed study of Dixon et al. (2009) reported that GSTs showing peroxidase activity are numerous and not limited to any class. Of 38 theta, phi, and tau class GSTs tested for GSH peroxidase activity against short-chain organic peroxides, only six were found to have undetectable activity (Table 3 ). Of the 32 with detectable peroxidase activity, most were also able to catalyze GSH conjugation to one or both of two model substrates (Dixon et al., 2009).
Table 2 | Kinetic properties of dehydroascorbate reductases from several plant species.

\begin{tabular}{|c|c|c|c|c|c|c|c|}
\hline \multirow{2}{*}{$\begin{array}{l}\text { Name/ } \\
\text { Subcellular } \\
\text { localization }\end{array}$} & \multirow{2}{*}{$\begin{array}{l}\text { Max } \\
\text { activity }\end{array}$} & \multicolumn{3}{|c|}{ GSH } & \multicolumn{3}{|c|}{ DHA } \\
\hline & & $\kappa_{\mathrm{M}}$ & $\begin{array}{l}\boldsymbol{k}_{\text {cat }} \\
\left(/ 10^{4}\right)\end{array}$ & $\begin{array}{l}k_{\text {cat }} / K_{\mathrm{M}} \\
\left(/ 10^{4}\right)\end{array}$ & $\kappa_{\mathrm{M}}$ & $\begin{array}{l}k_{\text {cat }} \\
\left(/ 10^{4}\right)\end{array}$ & $\begin{array}{l}k_{\text {cat }} / K_{\mathrm{M}} \\
\left(/ 10^{4}\right)\end{array}$ \\
\hline
\end{tabular}

\begin{tabular}{|c|c|c|c|c|c|c|c|}
\hline \multicolumn{8}{|c|}{ PURIFIED FROM SPINACH LEAVES } \\
\hline $\mathrm{Cyt}^{\mathrm{a}}$ & 370 & 2.5 & - & - & 0.07 & 0.01 & - \\
\hline Chp $p^{b}$ & 360 & 1.1 & - & - & 0.07 & 0.03 & - \\
\hline $\mathrm{Chp}^{\mathrm{C}}$ & - & 1.1 & - & 0.52 & 0.05 & 0.05 & 0.9 \\
\hline \multicolumn{8}{|c|}{ RECOMBINANT ARABIDOPSIS ENZYMES } \\
\hline DHAR1 Per & 936 & 10 & - & - & 0.26 & - & - \\
\hline DHAR2 Cyt & 120 & - & - & - & - & - & - \\
\hline DHAR3 Chp/Mit & 264 & 10 & - & - & 0.50 & - & - \\
\hline \multicolumn{8}{|c|}{ RECOMBINANT POPLAR ENZYMES } \\
\hline DHAR1 Chp & 53 & 3.8 & 9.9 & 2.7 & 0.07 & 1.3 & 18.8 \\
\hline DHAR2 Cyt & 50 & 2.3 & 5.4 & 2.4 & 0.23 & 1.8 & 7.7 \\
\hline DHAR3 Cyt & 38 & 2.5 & 4.1 & 1.7 & 0.48 & 2.1 & 4.4 \\
\hline \multicolumn{8}{|c|}{ RECOMBINANT RICE ENZYME ${ }^{f}$} \\
\hline DHAR1 Cyt & 350 & 1.0 & - & - & 0.35 & - & - \\
\hline
\end{tabular}

Values are expressed in $m M\left(K_{M}\right), s^{-1}\left(k_{c a t}\right), m M^{-1} s^{-1}\left(k_{c a t} / K_{M}\right)$, and $\mu m o l$. $\mathrm{min}^{-1} \mathrm{mg}^{-1}$ protein (maximal activity). Chp, chloroplast. Cyt, cytosol. Mit, mitochondrion. Per, peroxisome.

References: ${ }^{a}$ Hossain and Asada, 1984; ${ }^{b}$ Shimaoka et al., 2000; ' Shimaoka et al., 2003; ${ }^{d}$ Dixon et al., 2002; ${ }^{e}$ Tang and Yang, 2013; ${ }^{f}$ Amako et al., 2006.

Table 3 | Arabidopsis recombinant glutathione $S$-transferases shown to have GSH peroxidase activity in vitro.

\section{PEROXIDATIC ACTIVITY}

$\mathrm{T} 1>\mathrm{U} 25>\mathrm{T} 3>\mathrm{T} 2>\mathrm{U} 8>\mathrm{U} 17>\mathrm{U} 24>\mathrm{F} 6>\mathrm{F} 8>\mathrm{U} 6>\mathrm{U} 16>\mathrm{U} 5>$

$\mathrm{F} 2>\mathrm{F} 9>\mathrm{U} 18>\mathrm{U} 3>\mathrm{U} 19>\mathrm{U} 1>\mathrm{U} 22>\mathrm{F} 7>\mathrm{U} 4>\mathrm{F} 3>\mathrm{U} 20=\mathrm{U} 23>$ $\mathrm{U} 10=\mathrm{U} 26>\mathrm{U} 28=\mathrm{U} 2>\mathrm{U} 9>\mathrm{U} 7>\mathrm{U} 21>\mathrm{U} 13$

\section{PEROXIDATIC ACTIVITY NOT DETECTED}

\begin{tabular}{|c|c|c|c|c|c|}
\hline F5 & $\mathrm{F} 14$ & U11 & U12 & U14 & U27 \\
\hline \multicolumn{6}{|c|}{ PEROXIDATIC ACTIVITY NOT TESTED } \\
\hline F4 & $\mathrm{F} 13$ & F10 & F11 & $\mathrm{F} 12$ & U15 \\
\hline
\end{tabular}

The enzymes for which peroxidatic activity was detected are listed in descending order of the activity measured on a unit protein basis against cumene hydroperoxide (Dixon et al., 2009).

Although 32 GSTs showed peroxidase activity in vitro, their specific activities varied considerably, the most active (GSTT1) having rates $\sim 600$-fold higher than the least active (GSTU13). The relatively small theta class was the only one whose members were all found to be competent in GSH peroxidation. Together with the tau-type U25, these three GSTs showed the highest specific peroxidase activity (Table 3 ). Moreover, the theta class enzymes were active not only against cumene hydroperoxide but also against long-chain $\left(\mathrm{C}_{18}\right)$ fatty acid peroxides. This contrasted with U25, which was highly active only against the model peroxide (Dixon et al., 2009). Interestingly, the theta GSTs were shown to be localized in the peroxisomes (Figure 2), organelles that can have high rates of both peroxide generation and fatty acid metabolism. 


\section{Glutaredoxin-linked peroxiredoxins}

The activity of recombinant poplar mitochondrial PRXIIF against $\mathrm{H}_{2} \mathrm{O}_{2}$ and organic peroxides was measured in the presence of GSH and/or GRX (Gama et al., 2007). With tert-butyl hydroperoxide as oxidant, a $K_{\mathrm{M}}$ of $260 \mu \mathrm{M}$ was obtained for GSH. However, the activity was considerably stimulated by the additional presence of poplar GRX C4 (Gama et al., 2007). Analysis of the chloroplastic PRXIIE (Gama et al., 2008) revealed fairly similar properties, except that lower $K_{\mathrm{M}}$ peroxide and higher $k_{\text {cat }}$ values produced somewhat higher catalytic efficiencies than for the mitochondrial protein (Table 4). In fact, the kinetic properties against peroxide of the glutathione-linked PRXIIE were very similar to 2-cys PRX, which is also chloroplastic but glutathione-independent (Horling et al., 2003; Bernier-Villamor et al., 2004; Rouhier et al., 2004a,b; Gama et al., 2007). A study of the mitochondrial PRXIIF from pea reported a similar $K_{\mathrm{M}}$ for $\mathrm{H}_{2} \mathrm{O}_{2}$ but significantly higher turnover values (BarrancoMedina et al., 2007). The $K_{M}$ values for $\mathrm{H}_{2} \mathrm{O}_{2}$ of PRXII, 2-cys PRX and APX are quite similar, but the turnover rates of both types of PRX are significantly lower. Thus, $k_{\text {cat }} / K_{\mathrm{M}}$ values for PRX are about 100-fold below those measured for chloroplastic APX or, in the case of the pea PRXIIF, over 10-fold lower (Table 4).

In terms of the capacity for GSH oxidation through GRXPRXII compared to the ascorbate-glutathione pathway, it is interesting to compare the $k_{\text {cat }}$ and $k_{\text {cat }} / K_{\mathrm{M}}$ values of PRXII and DHAR obtained when the respective oxidants (peroxide and DHA) were varied. Based on available data, the parameters for DHAR are about 20-1000-fold higher (compare Tables 2, 4). For equal amounts of protein, this indicates that DHAR should be more efficient, although the actual in vivo rates will be influenced by several factors, most obviously the relative abundance of the proteins and the in vivo concentrations of the respective oxidants in the compartments where the proteins are located.

Glutaredoxins can catalyze reduction of DHA in vitro (Wells et al., 1990). Arabidopsis GRXC1 and C2, which are competent in regeneration of PRXIIB, can also catalyze DHA reduction (Riondet et al., 2012). $K_{\mathrm{M}}$ values of the GRX for DHA were similar to DHAR but the $k_{\text {cat }}$ values were only about $3 \mathrm{~s}^{-1}$ (Riondet et al., 2012), several orders of magnitude lower than the DHARs (Table 2).

\section{GENE EXPRESSION DURING OXIDATIVE STRESS}

There have been many transcriptomic analyses of plants undergoing oxidative stress, conditions in which oxidation of GSH is expected to be accelerated. However, the number of such studies that have included data on glutathione status is more limited. These notably include Arabidopsis mutants deficient in the major leaf form of catalase (CAT2), in which conditionally increased $\mathrm{H}_{2} \mathrm{O}_{2}$ availability through photorespiration drives reproducible changes in GSSG:GSH (Mhamdi et al., 2010a). These increases in leaf GSSG are also observed, to a lesser extent, in knockout mutants for GR1, and are particularly marked in cat 2 gr 1 double mutants lacking both enzymes (Figure 3). However, the processes that are responsible for GSSG accumulation when CAT2 function is lost remain unclear.

As a first step to investigating this question, we mined two Arabidopsis cat 2 microarray datasets for genes encoding the enzymes listed in Supplemental Table 1. The data on cat2 were compared with responses to external $\mathrm{H}_{2} \mathrm{O}_{2}$, ozone, and paraquat (Figure 4C) and to results obtained for the flu mutant, which generates excess singlet oxygen in the chloroplast (Figure 4D). Experimental details for all these microarray studies are given in Supplemental Table 2. The two datasets in Figures 4A,B come from different experiments performed on leaf rosette material from plants of different age (Mhamdi et al., 2010b; Queval et al., 2012). They were also obtained using two different microarray chips, and some probe sets were present on only one of the chips (Figure 4: absence of corresponding probe sets is indicated by white rows). Moreover, key factors determining the measured response to oxidative stress are likely to be exposure time and stress intensity. As well as other differences in plant growth conditions, the data shown in the different parts of Figure 4 were obtained after different exposure times, ranging from $1 \mathrm{~h}\left(\mathrm{H}_{2} \mathrm{O}_{2}\right.$; Figure 4C) to 4 days (Figures 4A,B, right column).

For all the above reasons, some divergence is expected between responses observed in the different datasets. Despite this, a number of genes within each family responded quite similarly to

Table 4 | Kinetic chacteristics of glutaredoxin-dependent peroxiredoxins from poplar and pea.

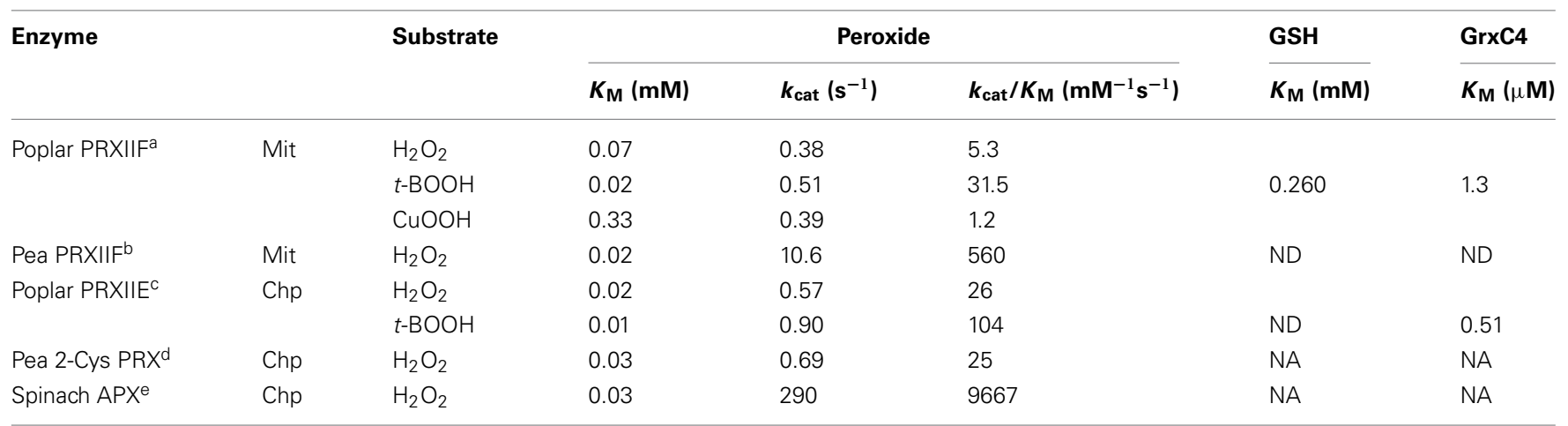

For comparison, data are shown for 2-cys peroxiredoxin from pea (Pisum sativum) and ascorbate peroxidase (APX) from spinach (Spinacia oleracea). $t$-BOOH, tertbutyl hydroperoxide. $\mathrm{CuOOH}$, cumene hydroperoxide. ND, not determined. NA, not applicable.

References: ${ }^{a}$ Gama et al., 2007; 'b Barranco-Medina et al., 2007; c Gama et al., 2008; d Bernier-Villamor et al., 2004 ; e Nakano and Asada, 1987. 


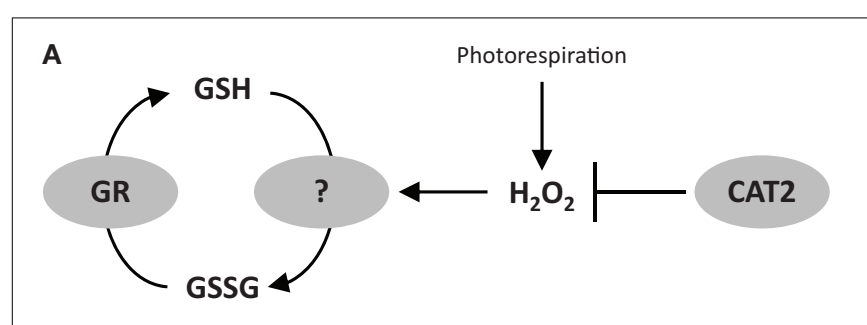

B

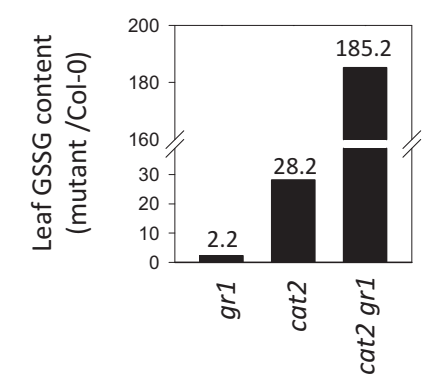

FIGURE 3 | Accumulation of GSSG relative to Col-0 in Arabidopsis knockout mutants for glutathione reductase 1 (gr1), catalase 2 (cat2), or both (cat2 gr1). (A)Simple scheme showing the interplay between GR and $\mathrm{H}_{2} \mathrm{O}_{2}$-triggered oxidation in determining the balance between $\mathrm{GSH}$ and GSSG in the mutant systems. (B) Leaf GSSG contents in the three mutant lines relative to Col-0 controls. Fold-change compared to Col-0 GSSG contents are indicated above the bars.

the different oxidative stresses. Among the three DHARs, DHAR2 was the most obviously responsive, being clearly induced in cat2, $f l u$, and by external $\mathrm{H}_{2} \mathrm{O}_{2}$ or paraquat. Induction was less evident following ozone exposure (Figure 4). PRXIIC was the only GRXlinked PRX that was induced, though only in response to ozone. None of the PRXII genes were induced alongside GSSG accumulation in cat2 (Figures 4A,B). In contrast, marked up-regulation of several GSTs was observed in most of the datasets. GSTs that responded to most of the treatments included $\mathrm{F} 6$ and $\mathrm{F} 7$, as well as many tau types, with U1, U4, U5, U6, U7, U8, U24, and U25 showing a particularly clear induction. Indeed, U24 and U25 are among the most strongly cat2-induced genes on a fold-change basis (Queval et al., 2012). Interestingly, U11, U12, and U13 were induced by all treatments except in cat2 and cat2 gr1 (Figure 4, compare $\mathrm{A}$ and $\mathrm{B}$ with $\mathrm{C}$ and $\mathrm{D}$ ). This could indicate that these GSTs are involved in early responses to oxidative stress. In contrast to several phi and tau GST genes, none of the theta types were induced in any condition, despite their documented high peroxidase activity (Table 3 ). Little or no induction of GSNOR was apparent, while among the GPX sequences, GPX5, GPX6, and GPX7 were most obviously responsive, although some variation was observed between the experiments, including the two cat2 datasets.

This comparison points to numerous candidates that could play a role in oxidizing glutathione. For several reasons, however, the expression data remain at best indicative. First, increased transcripts may not feed through to an increase in protein abundance. Second, transcriptomic analyses do not identify other possible regulatory mechanisms that may operate during oxidative stress at the post-transcriptional or post-translational levels. Third, the data of Figure 4 show fold-changes compared to wild-type: even if strongly induced at the protein level, low abundance enzymes may not make a marked contribution to GSH oxidation within the cellular context. Inversely, it is not possible to discount a role for an enzyme on the basis of lack of induction. Finally, even if transcript up-regulation feeds through to enhanced protein, some of the enzyme activities encoded by responsive genes shown in Figure 4 may not involve GSH oxidation. At least some of the GSTs are probably induced in connection with a conjugase function. For example, GSTF6 has been implicated in the synthesis of camalexin (Su et al., 2011), a phytoalexin that can accumulate strongly in cat 2 in oxidative stress conditions (Chaouch et al., 2010). As noted above, GPXs may mainly if not exclusively catalyze peroxidation using TRX, not GSH.

With the above caveats in mind, useful pointers can be obtained by combining information from biochemical competence and efficiency (Tables 2-4) with responsiveness at the transcript level (Figure 4). Some examples of possible candidates identified according to these criteria would include DHAR2, GSTU8, GSTU24, and GSTU25. Interestingly, the proteins encoded by these genes are cytosolic (Figure 2), even though the initial location of oxidant generation in several of the studies shown in Figure 4 is expected to be mainly peroxisomal (cat2) or chloroplastic (paraquat, $f l u$ ). The potential importance of cytosolic pathways in determining glutathione status in cat 2 has been previously noted (Mhamdi et al., 2010b).

\section{GENETIC STUDIES}

While the data discussed above provide useful information on biochemical properties and expression patterns, establishing the physiological importance of specific components will require other approaches such as reverse genetics. Gene-specific loss-offunction studies will be required to establish the contributions of particular enzymes to GSSG production. As yet, there is relatively little information on the response of glutathione pools in plants specifically deficient in the genes discussed above. A few studies in Arabidopsis have generated potentially relevant data. A preliminary analysis of a dhar2 mutant reported that although DHA was somewhat increased compared to Col-0, GSSG levels were similar in the two lines (Yoshida et al., 2006). Loss of PRXIIF function had slight effects on root glutathione pools in control conditions, but little difference from wild-type was observed during stresses involving exposure to cadmium or to an inhibitor of the mitochondrial alternative oxidase (Finkemeier et al., 2005). Knockout Arabidopsis gstu17 mutants that showed altered stress responses were reported to have increased root and shoot glutathione contents in unstressed conditions, although no data for glutathione redox state or glutathione contents during stress were presented (Chen et al., 2012).

While loss-of-function studies are a more incisive approach to establishing the roles of specific genes, overexpression studies can also provide useful indications of the potential importance of a given enzyme. Several studies have overexpressed genes encoding GSTs, GPX, or DHAR, often with the objective of improving plant stress tolerance. A comprehensive discussion of these studies is beyond the scope of the present review. Hence, we limit ourselves here to reports that have included effects on glutathione status in the overexpressing lines. 
C

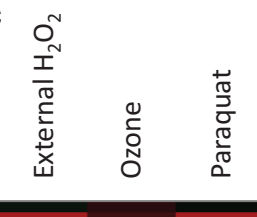

D

$\frac{\pi}{2}$

A

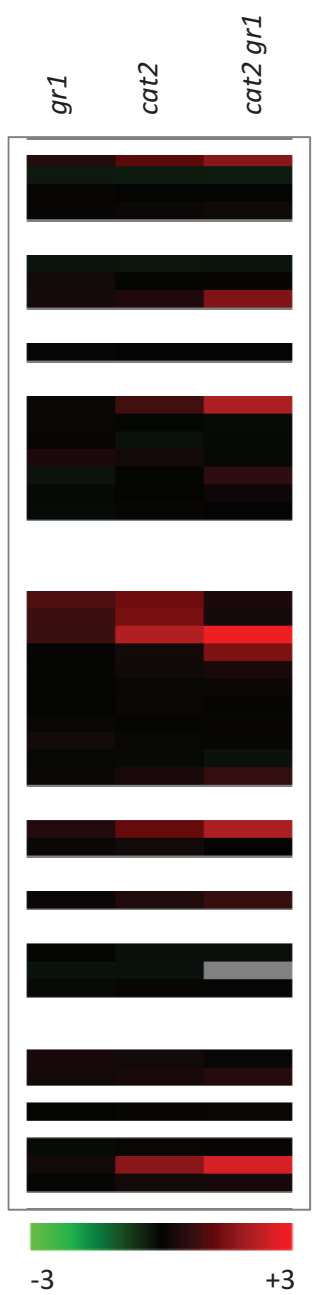

B
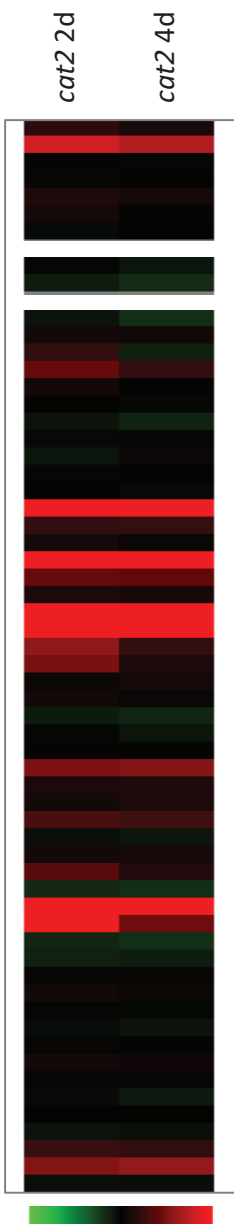

$-3$
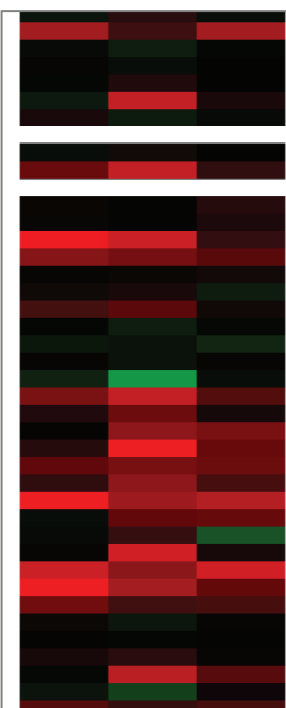

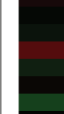

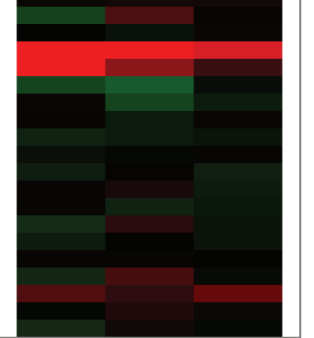

$-3$
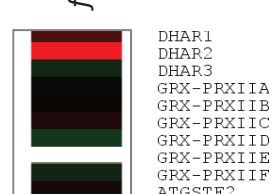

ATGSTY2

ATGSTF2
ATGSTF 3
ATGSTE

ATGSTF 4
ATGST 5
ATGSTI

ATGSTF 6
ATGSTF7

ATGSTF 7
ATGSF
ATGSTC

ATGSTF9
ATGSTF10

ATGSTF10

ATGSTF11
ATGSTF12

ATGSTF12
ATGSTF13
ATGSTF14

ATGSTF14

ATGSTI2
ATGSTU3

ATGSTU3
ATGSTU4

ATGSTU4
ATGSTU5

ATGSTU6
ATGSTU7

ATGSTU7
ATSTIU8
ATSTUG

ATGSTU9

ATGSTU10

ATGSTU1

ATGSTU13
ATGSTU14
ATSTI15

ATGSTU14
ATGSTU15
ATGSTU16

ATGSTU16

ATGSTU17
ATGSTU18

ATGSTU19

ATGSTU20
ATGSTU2

ATGSTU21

ATGSTU23

ATGSTU24
ATGSTU25

ATGSTU26
ATGSTU27

ATGSTU28

GSTT1

$\underset{\substack{\text { GSTT2 } \\ \text { GSTT3 }}}{\text { GSTSP }}$

GSTT3
GSNOR
ATGPX

$\underset{A T G P X 2}{A T G P X 1}$

ATGPX2
ATGPX3
ATGPX1

ATGPX4
ATGPX5

ATGPX5
ATEPX6
ATGPX7

ATGPX7
ATGPX8

FIGURE 4 | Expression of candidate genes involved in glutathione oxidation in GSSG-accumulating and/or oxidative stress mutants and in conditions promoting oxidative stress. Transcript abundance are shown as $\log _{2}$ values compared to control (wild-type or untreated). Experimental details are given in Supplemental Table 1. Red and green indicate induction and repression according to the scales shown at the bottom. White rows indicate absence of a corresponding probe set from the array chip. "GRX-PRXII" denotes the signals for the indicated PRX.
(A) GSSG-accumulating lines shown in Figure 2 (gr1, cat2, cat2 gr1). Oxidative stress was induced in 3 week old plants (Mhamdi et al., 2010b). (B) Two independent datasets for cat2 at two timepoints after onset of oxidative stress (2 and 4 days). Oxidative stress was induced in 5 week old plants (Queval et al., 2012). (C) Genevestigator data for chemically and environmentally induced oxidative stress ( $\mathrm{H} 2 \mathrm{O} 2$, paraquat and ozone). (D) Genevestigator data for the singlet oxygen-accumulating flu mutant (Laloi et al., 2007).
Tobacco knockdown and overexpressor DHAR lines showed a substantial decrease and increase in extractable foliar activity, respectively (Chen and Gallie, 2005). While the knockdown lines had decreased ascorbate and increased DHA, the opposite effect was observed in the overexpressors (Chen and Gallie, 2005). The GSH:GSSG ratio was lower in the knockdowns and higher in the overexpressors, with overexpression increasing GSH:GSSG from about 4 in the control plants to almost 20, an effect largely due to increased GSH rather than decreased GSSG (Chen and Gallie, 2005). Another study in tobacco also reported that overexpression of Arabidopsis DHAR2 increased the reduction state of the ascorbate pool, an effect that was observed both in control conditions and in response to aluminum stress (Yin et al., 2010). However, no difference in glutathione redox state between the control and overexpressors was observed in either condition. The authors concluded that GSH was not limiting for DHAR activity (Yin et al., 2010). Arabidopsis lines homologously overexpressing DHAR have also been described (Wang et al., 2010). Alongside improved stress tolerance, these plants had increased total pools of ascorbate and glutathione, both in control and stress conditions (high temperature, paraquat; Wang et al., 2010).

The picture that emerges from these studies is complex. If the reaction is considered in isolation, a negative relationship between the GSH:GSSG ratio and DHAR activity would be 
predicted, because the enzyme consumes GSH and produces GSSG. So far, there is little evidence that this relationship is observed in plants with genetically altered DHAR capacity. The reported increases in total glutathione and GSH:GSSG in tobacco and Arabidopsis overexpressor lines could be partly related to the need for enhanced GSH to support increased DHAR activity (Chen and Gallie, 2005; Wang et al., 2010). Thus, the effects of genetic manipulation of DHAR may not be limited to direct effects on GSH:GSSG ratios, e.g., because the plant may also respond by increasing glutathione synthesis. Another complication could be that altering the capacity of a single antioxidative enzyme may produce indirect effects on ROS availability that then alter the flux through other pathways that oxidize GSH, thus masking more direct effects.

Glutathione status was also assessed in tobacco lines overexpressing a GST with GSH peroxidase activity (Roxas et al., 2000). These lines showed enhanced tolerance to salt. Both in control and salt-stressed conditions, GST overexpression caused a more than three-fold increase in GSSG relative to control plants. This study therefore revealed that enhanced GST expression, which is a feature of oxidative stress responses (Figure 4), is able to decrease the reduction state of glutathione in vivo. It also reported the operation of secondary effects within the antioxidant system. Increased GSSG was associated with enhanced activities of ascorbate-glutathione pathway enzymes such as APX and MDHAR (Roxas et al., 2000).

\section{MODIFICATIONS OF GLUTATHIONE STATUS ASSOCIATED WITH GSSG ACCUMULATION}

Why does GSSG accumulate during oxidative stress? Given the existence of opposing GSH oxidation and GSSG reduction activities, such accumulation is unlikely to be a simple result of conversion of GSH to GSSG. Rather, it is probably more accurately viewed as the net outcome of oxidation outpacing reduction, even if only slightly. As a simple hypothetical example: if enhanced $\mathrm{H}_{2} \mathrm{O}_{2}$ drives oxidation of $2 \mathrm{GSH}$ to $\mathrm{GSSG}$ at $20 \mathrm{nmol.g}{ }^{-1} \mathrm{FW}$ $\mathrm{min}^{-1}$ (which even if one considers only DHAR as a source of GSSG is no more than $1 \%$ of typical capacities measured in vitro) but the in vivo GR activity is $1 \%$ slower $\left(19.8 \mathrm{nmol}^{-1} \mathrm{FW} \mathrm{min}^{-1}\right.$; about $2 \%$ of typical in vitro capacities), the two rates would entail a net accumulation of about $0.3 \mu \mathrm{mol}$.GSSG $\mathrm{g}^{-1} \mathrm{FW}$ in $24 \mathrm{~h}$. GSSG accumulation of this magnitude can be observed in catalase-deficient plants following transfer to oxidative stress conditions. The above calculation is obviously simplistic as the rates of the two reactions will vary as a function of changes in substrate concentrations following the onset of stress, and kinetic modeling would be required to examine the question more closely. It is intended merely to illustrate that slightly lower activity of GSSG reduction compared to GSH oxidation may be one factor driving a drop in the GSH: GSSG ratio in vivo.

In many cases, stress-induced GSSG accumulation in plants does not occur at the expense of decreased GSH. Rather, the GSH pool remains rather constant while even marked increases in total glutathione are almost entirely due to the accumulation of GSSG (Smith et al., 1985; Willekens et al., 1997; Mhamdi et al., 2010a). Available data suggest that this involves at least two processes additional to redox cycling between GSH and GSSG. The first is increased GSH neosynthesis as a result of processes that probably involve activation of cysteine and glutathione production at transcriptional and post-translational levels (Bick et al., 2001; Hicks et al., 2007; Gromes et al., 2008; Queval et al., 2009). The second is a marked change in glutathione compartmentation, with GSSG accumulation occurring particularly in the vacuole (Queval et al., 2011). This second process means that the GSH:GSSG ratio measured in tissue or whole cell extracts does not report on the actual glutathione status in specific compartments but is rather a composite value of GSH:GSSG ratios, which may differ widely between different subcellular locations (Noctor et al., 2013). For example, the cytosolic glutathione pool may well be less oxidized than that measured in extracts because a substantial amount of the GSSG generated by oxidative stress is shipped to the vacuole, possibly by ABCC transporters (Martinoia et al., 1993; Lu et al., 1998). This does not necessarily invalidate the GSSG:GSH ratio as a useful oxidative stress marker, because accumulation at sites such as the vacuole is predicted to be dependent on GSSG accumulation in other compartments caused by the oxidant-driven imbalance discussed above.

Figure 5 presents an overview that attempts to integrate some of the different processes that are likely to be involved in oxidative stress-driven changes in glutathione status. As well as GR activity, oxidation by the three main pathways we have discussed in this review is situated within the context of glutathione synthesis and the vacuolar sequestration of a substantial part of the GSSG that is generated. It is noteworthy that the vacuole is not the only compartment in which GSSG is highly enriched during oxidative stress. Marked accumulation of GSSG also seems to occur in

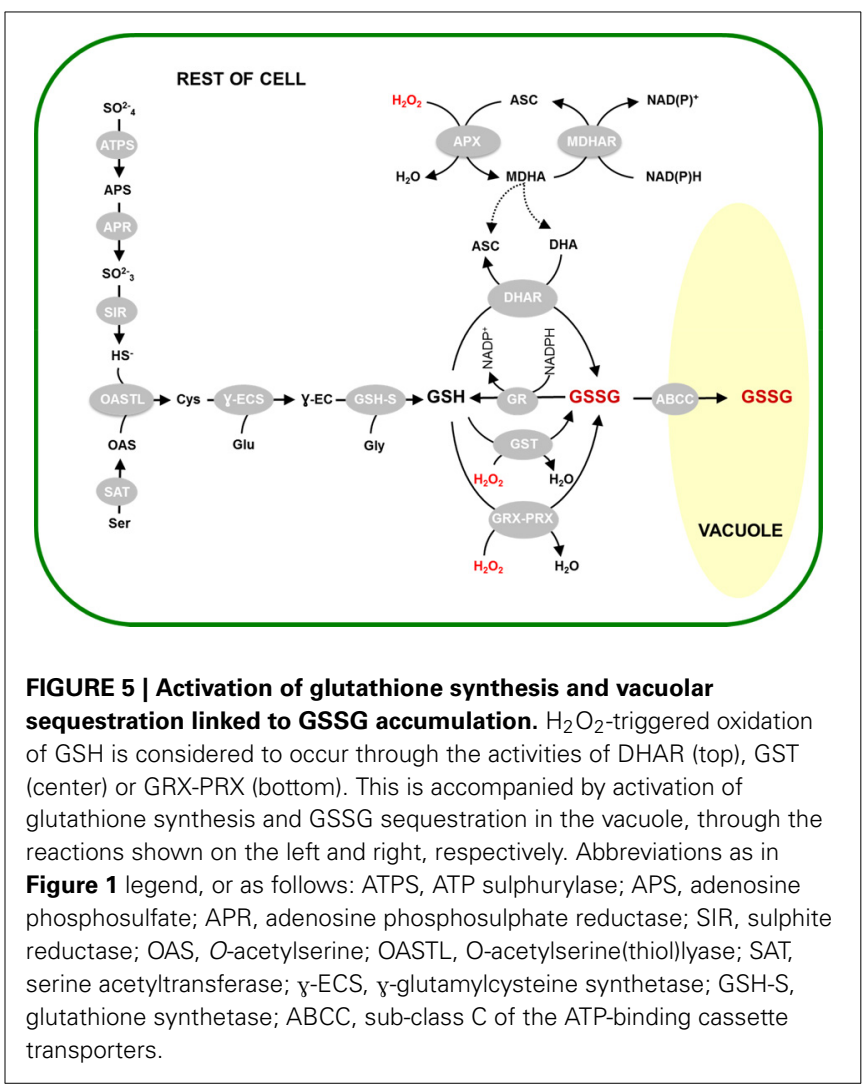


the chloroplast. This has been reported in two independent studies of catalase-deficient plants using different techniques, despite the fact that the initial increase in $\mathrm{H}_{2} \mathrm{O}_{2}$ availability in these systems is expected to be extra-chloroplastic (Smith et al., 1985; Queval et al., 2011). While GSSG import from the cytosol cannot be completely discounted, the most influential process may be oxidation of GSH within the chloroplast (Noctor et al., 2013). Whatever the mechanisms, oxidation of GSH and/or accumulation of GSSG in the chloroplast may have consequences for thiol-dependent reactions in this compartment. These include regulation of chloroplast proteins by $S$-glutathionylation reactions or the TRX system (Dixon et al., 2005; Michelet et al., 2005; Zaffagnini et al., 2012) as well as activation of synthesis pathways that contribute to the accumulation of total glutathione in these conditions (Figure 5).

\section{CONCLUSIONS AND PERSPECTIVES}

The post-genomics era has witnessed a dramatic increase in our understanding of plant antioxidative systems. Work over the last decade has also underscored their complexity. The present discussion has attempted to emphasize that a multiplicity of reactions may contribute to GSH oxidation during oxidative stress, leading to modifications in the status of this potentially important cellular redox signal. Whatever the reactions involved, the resulting changes in GSH:GSSG triggered by oxidants such as $\mathrm{H}_{2} \mathrm{O}_{2}$ may be signaled to sensitive proteins by catalysts such as certain GRX. Alternatively, the oxidation of certain thiol-dependent peroxidases, including some we have mentioned here, may itself act as a signal or signal relay independent of "bulk-phase" changes in GSH:GSSG.

While DHAR function in the ascorbate-glutathione pathway remains an outstanding candidate as a GSSG-generating enzyme, data from biochemical, transcriptomic and reverse genetics studies all suggest that other enzymes may contribute. The potential for redundancy between different enzyme classes is evident. It is also possible that considerable genetic redundancy exists within enzyme classes, both in peroxide removal and in GSH oxidation. This is most obviously apparent for the large GST family. Moreover, identification of the enzymes specifically involved in GSH oxidation using targeted loss-of-function studies may be complicated by the existence of different pathways that are able to replace or compensate for one another.

Despite these complexities, establishing the importance of the pathways able to generate GSSG from GSH in planta should be favored by the wide range of gene-specific mutants now available in Arabidopsis and other species. Kinetic modeling could also be useful to evaluate interactions between different reactions, and to define the limits of a system in which numerous components may act in parallel. A key issue could be (sub)cellular compartmentation, both of the reactions that cause GSH oxidation and of the GSSG that accumulates as a result. GSH-oxidizing processes may be condition-specific, with some reactions being more important in certain stresses than in others. Other issues that will need to be taken into account are the stage of plant development as well as modulating environmental conditions such as photoperiod, factors that may impose different patterns of gene expression in response to oxidative stress.

\section{SUPPLEMENTARY MATERIAL}

The Supplementary Material for this article can be found online at: http://www.frontiersin.org/journal/10.3389/fpls.2013. 00477/abstract

\section{REFERENCES}

Amako, K., Ushimaru, T., Ishikawa, A., Ogishi, Y., Kishimoto, R., and Goda, K. (2006). Heterologous expression of dehydroascorbate reductase from rice and its application to determination of dehydroascorbate concentrations. J. Nutr. Sci. Vitaminol. 52, 89-95. doi: 10.3177/jnsv.52.89

Asada, K., and Takahashi, M. (1987). "Production and scavenging of active oxygen species in photosynthesis," in Photoinhibition, eds D. Kyle, C. Osmond, and C. Arntzen (NewYork, NY: Elsevier Science Publishers), 227-287.

Barranco-Medina, S., Krell, T., Finkemeier, I., Sevilla, F., Lázaro, J. J., and Dietz, K. J. (2007). Biochemical and molecular characterization of the mitochondrial peroxiredoxin PsPrxII F from Pisum sativum. Plant Physiol. Biochem. 45, 729-739. doi: 10.1016/j.plaphy.2007.07.017

Barroso, J. B., Corpas, F. J., Carreras, A., Rodríguez-Serrano, M., Esteban, F. J., Fernández-Ocaòa, A., et al. (2006). Localization of S-nitrosoglutathione and expression of $S$-nitrosoglutathione reductase in pea plants under cadmium stress. J. Exp. Bot. 57, 1785-1793. doi: 10.1093/jxb/erj175

Bernier-Villamor, L., Navarro, E., Sevilla, F., and Lázaro, J. J. (2004). Cloning and characterization of a 2-Cys peroxiredoxin from Pisum sativum. J. Exp. Bot. 55, 2191-2199. doi: 10.1093/jxb/erh238

Bick, J. A., Aslund, F., Chen, Y., and Leustek, T. (1998). Glutaredoxin function for the carboxyl-terminal domain of the plant-type 5'-adenylylsulfate reductase. Proc. Natl. Acad. Sci. U.S.A. 95, 8404-8409. doi: 10.1073/pnas.95. 14.8404

Bick, J. A., Setterdahl, A. T., Knaff, D. B., Chen, Y., Pitcher, L. H., Zilinskas, B. A., et al. (2001). Regulation of the plant-type 5'-adenylyl sulfate reductase by oxidative stress. Biochemistry 40, 9040-9048. doi: 10.1021/bi010518v

Bors, W., Heller, W., Michel, C., and Saran, M. (1990). "Flavonoids as antioxidants: determination of radical-scavenging efficiencies," in Oxygen Radicals in Biological Systems: Oxygen Radicals and Antioxidants, Methods in Enzymology, Vol. 186, eds L. Packer and A. N. Glazer (New York, NY: Elsevier Science Publishers), 343-355. doi: 10.1016/0076-6879(90)86128-I

Bréhélin, C., Meyer, E. H., de Souris, J. P., Bonnard, G., and Meyer, Y. (2003). Resemblance and dissemblance of Arabidopsis type II peroxiredoxins: similar sequences for divergent gene expression, protein localization, and activity. Plant Physiol. 132, 2045-2057. doi: 10.1104/pp.103.022533

Cairns, N. G., Pasternak, M., Wachter, A., Cobbett, C. S., and Meyer, A. J. (2006). Maturation of Arabidopsis seeds is dependent on glutathione biosynthesis within the embryo. Plant Physiol. 141, 446-455. doi: 10.1104/pp.106. 077982

Chaouch, S., Queval, G., Vanderauwera, S., Mhamdi, A., Vandorpe, M., LangloisMeurinne, M., et al. (2010). Peroxisomal hydrogen peroxide is coupled to biotic defense responses by ISOCHORISMATE SYNTHASE 1 in a daylength-related manner. Plant Physiol. 153, 1692-1705. doi: 10.1104/pp.110.153957

Chen, J. H., Jiang, H. W., Hsieh, E. J., Chen, H. Y., Chien, C. T., Hsieh, H. L., et al. (2012). Drought and salt stress tolerance of an Arabidopsis glutathione $S$-transferase U17 knockout mutant are attributed to the combined effect of glutathione and abscisic acid. Plant Physiol. 158, 340-351. doi: 10.1104/pp.111.181875

Chen, Z., and Gallie, D. R. (2005). Increasing tolerance to ozone by elevating foliar ascorbic acid confers greater protection against ozone than increasing avoidance. Plant Physiol. 138, 1673-1689. doi: 10.1104/pp.105.062000

Chew, O., Whelan, J., and Millar, A. H. (2003). Molecular definition of the ascorbate-glutathione cycle in Arabidopsis mitochondria reveals dual targeting of antioxidant defenses in plants. J. Biol. Chem. 278, 46869-46877. doi: 10.1074/jbc.M307525200

Collin, V., Lamkemeyer, P., Miginiac-Maslow, M., Hirasawa, M., Knaff, D. B., Dietz, K. J., et al. (2004). Characterization of plastidial thioredoxins from Arabidopsis belonging to the new y-type. Plant Physiol. 136, 4088-4095. doi: 10.1104/pp.104.052233

Couturier, J., Ströher, E., Albetel, A. N., Roret, T., Muthuramalingam, M., Tarrago, L., et al. (2011). Arabidopsis chloroplastic glutaredoxin C5 as a model to explore molecular determinants for iron-sulfur cluster binding into glutaredoxins. J. Biol. Chem. 286, 27515-27527. doi: 10.1074/jbc.M111.228726 
Cummins, I., Cole, D. J., and Edwards, R. (1999). A role for glutathione transferases functioning as glutathione peroxidases in resistance to multiple herbicides in black-grass. Plant J. 18, 285-292. doi: 10.1046/j.1365-313X.1999. 00452. $x$

Cummins, I., Hagan, D. O., Jablonkai, I., Cole, D. J., Hehn, A., Werck-Reichhart, D., et al. (2003). Cloning, characterization and regulation of family of phi class glutathione transferases from wheat. Plant Mol. Biol. 52, 591-603. doi: 10.1023/A:1024858218804

Dayer, R., Fischer, B. B., Eggen, R. I. L., and Lemaire, S. D. (2008). The peroxiredoxin and glutathione peroxidase families in Chlamydomonas reinhardtii. Genetics 179, 41-57. doi: 10.1534/genetics.107.086041

DeRidder, B. P., Dixon, D. P., Beussman, D. J., Edwards, R., and Goldsbrough, P. B. (2002). Induction of glutathione $S$-transferases in Arabidopsis by herbicide safeners. Plant Physiol. 130, 1497-1505. doi: 10.1104/pp.010066

Dghim, A. A., Mhamdi, A., Vaultier, M. V., Hasenfratz-Sauder, M. P., Le Thiec, D., Dizengremel, P., et al. (2013). Analysis of cytosolic isocitrate dehydrogenase and glutathione reductase 1 in photoperiod-influenced responses to ozone using Arabidopsis knockout mutants. Plant Cell Environ. 36, 1981-1991. doi: 10.1111/pce.12104

Díaz, M., Achkor, H., Titarenko, E., and Martínez, M. C. (2003). The gene encoding glutathione-dependent formaldehyde dehydrogenase/GSNO reductase is responsive to wounding, jasmonic acid and salicylic acid. FEBS Lett. 543, 136-139. doi: 10.1016/S0014-5793(03)00426-5

Dietz, K. J. (2003). Plant peroxiredoxins. Annu. Rev. Plant Biol. 54, 93-107. doi: 10.1146/annurev.arplant.54.031902.134934

Dietz, K. J., Horling, F., König, J., and Baier, M. (2002). The function of the chloroplast 2-cysteine peroxiredoxin in peroxide detoxification and its regulation. J. Exp. Bot. 53, 1321-1329. doi: 10.1093/jexbot/53.372.1321

Di Mascio, P., Kaiser, S., and Sies, H. (1989). Lycopene as the most efficient biological carotenoid singlet oxygen quencher. Arch. Biochem. Biophys. 274, 532-538. doi: 10.1016/0003-9861(89)90467-0

Dipierro, S., and Borranccino, G. (1991). Dehydroascorbate reductase from potato tubers. Phytochemistry 30, 427-429. doi: 10.1016/0031-9422(91) 83698-K

Dixon, D. P., Davis, B. G., and Edwards, R. (2002). Functional divergence in the glutathione transferase superfamily in plants. Identification of two classes with putative functions in redox homeostasis in Arabidopsis thaliana. J. Biol. Chem. 277, 30859-30869. doi: 10.1074/jbc.M202919200

Dixon, D. P., and Edwards, R. (2010). "Glutathione S-transferases," in The Arabidopsis Book (Rockville, MD: American Society of Plant Biologists). Available online at: http://www.aspb.org/publications/arabidopsis/.

Dixon, D. P., Hawkins, T., Hussey, P. J., and Edwards, R. (2009). Enzyme activities and subcellular localization of members of the Arabidopsis glutathione transferase superfamily. J. Exp. Bot. 60, 1207-1218. doi: 10.1093/jxb/ ern365

Dixon, D. P., Skipsey, M., Grundy, N. M., and Edwards, R. (2005). Stress-induced protein S-glutathionylation in Arabidopsis. Plant Physiol. 138, 2233-2244. doi: 10.1104/pp.104.058917

Edwards, E. A., Rawsthorne, S., and Mullineaux, P. M. (1990). Subcellular distribution of multiple forms of glutathione reductase in leaves of pea (Pisum sativum L.). Planta 180, 278-284. doi: 10.1007/BF00194008

Edwards, R., Blount, J. W., and Dixon, R. A. (1991). Glutathione and elicitation of the phytoalexin response in legume cell cultures. Planta 184, 403-409. doi: 10.1007/BF00195343

Eshdat, Y., Holland, D., Faltin, Z., and Ben-Hayyim, G. (1997). Plant glutathione peroxidases. Physiol. Plant. 100, 234-240. doi: 10.1111/j.13993054.1997.tb04779.x

Finkemeier, I., Goodman, M., Lamkemeyer, P., Kandlbinder, A., Sweetlove, L. J., and Dietz, K. J. (2005). The mitochondrial type II peroxiredoxin F is essential for redox homeostasis and root growth of Arabidopsis thaliana under stress. J. Biol. Chem. 280, 12168-12180. doi: 10.1074/jbc.M413189200

Foyer, C. H., and Halliwell, B. (1977). Purification and properties of dehydroascorbate reductase from spinach leaves. Phytochemistry 16, 1347-1350. doi: 10.1016/S0031-9422(00)88779-8

Foyer, C. H., and Noctor, G. (2011). Ascorbate and glutathione: the heart of the redox hub. Plant Physiol. 155, 2-18. doi: 10.1104/pp.110.167569

Gama, F., Bréhélin, C., Gelhaye, E., Meyer, Y., Jacquot, J. P., Rey, P., et al. (2008). Functional analysis and expression characteristics of chloroplastic Prx IIE. Plant Physiol. 133, 599-610. doi: 10.1111/j.1399-3054.2008.01097.x
Gama, F., Keech, O., Eymery, F., Finkemeier, I., Gelhaye, E., Gardeström, P., et al. (2007). The mitochondrial type II peroxiredoxin from poplar. Physiol. Plant. 129, 196-206. doi: 10.1111/j.1399-3054.2006.00785.x

Gomez, L., Vanacker, H., Buchner, P., Noctor, G., and Foyer, C. H. (2004). The intercellular distribution of glutathione synthesis and its response to chilling in maize. Plant Physiol. 134, 1662-1671. doi: 10.1104/pp.103.033027

Gromes, R., Hothorn, M., Lenherr, E. D., Rybin, V., Sheffzek, K., and Rausch, T. (2008). The redox switch of $\gamma$-glutamylcysteine ligase via a reversible monomerdimer transition is a mechanism unique to plants. Plant J. 54, 1063-1075. doi: 10.1111/j.1365-313X.2008.03477.x

Grzam, A., Tennstedt, P., Clemens, S., Hell, R., and Meyer, A. J. (2006). Vacuolar sequestration of glutathione S-conjugates outcompetes a possible degradation of the glutathione moiety by phytochelatin synthase. FEBS Lett. 580, 6384-6390. doi: 10.1016/j.febslet.2006.10.050

Han, Y., Mhamdi, A., Chaouch, S., and Noctor, G. (2013a). Regulation of basal and oxidative stress-triggered jasmonic acid-related gene expression by glutathione. Plant Cell Environ.. 36, 1135-1146. doi: 10.1111/pce.12048

Han, Y., Chaouch, S., Mhamdi, A., Queval, G., Zechmann, B., and Noctor, G. (2013b). Functional analysis of Arabidopsis mutants points to novel roles for glutathione in coupling $\mathrm{H}_{2} \mathrm{O}_{2}$ to activation of salicylic acid accumulation and signaling. Antioxid. Redox Signal. 18, 2106-2121. doi: 10.1089/ars.2012.5052

Hausladen, A., and Kunert, K. J. (1990). Effects of artificially enhanced levels of ascorbate and glutathione on the enzymes monodehydroascorbate reductase, dehydroascorbate reductase, and glutathione reductase in spinach (Spinacia oleracea). Plant Physiol. 79, 384-388. doi: 10.1111/j.1399-3054.1990.tb06757.x

Herbette, S., Lenne, C., Leblanc, N., Julien, J. L., Drevet, J. R., and RoeckelDrevet, P. (2002). Two GPX-like proteins from Lycopersicon esculentum and Helianthus annuus are antioxidant enzymes with phospholipid hydroperoxide glutathione peroxidase and thioredoxin peroxidase activities. Eur. J. Biochem. 269, 2414-2420. doi: 10.1046/j.1432-1033.2002.02905.x

Hicks, L. M., Cahoon, R. E., Bonner, E. R., Rivard, R. S., Sheffield, J., and Jez, J. M. (2007). Thiol-based regulation of redox-active glutamate-cysteine ligase from Arabidopsis thaliana. Plant Cell 19, 2653-2661. doi: 10.1105/tpc.107. 052597

Horling, F., Lamkemeyer, P., König, J., Finkemeier, I., Kandlbinder, A., Baier, M., et al. (2003). Divergent light-, ascorbate-, and oxidative stress-dependent regulation of expression of the peroxiredoxin gene family in Arabidopsis. Plant Physiol. 131, 317-325. doi: 10.1104/pp.010017

Hossain, M. A., and Asada, K. (1984). Purification of dehydroascorbate reductase from spinach and its characterisation as a thiol enzyme. Plant Cell Physiol. 25 , 85-92.

Iqbal, A., Yabuta, Y., Takeda, T., Nakano, Y., and Shigeoka, S. (2006). Hydroperoxide reduction by thioredoxin-specific glutathione peroxidase isoenzymes of Arabidopsis thaliana. FEBS J. 273, 5589-5597. doi: 10.1111/j.17424658.2006.05548.x

Jiménez, A., Hernández, J. A., del Río, L., and Sevilla, F. (1997). Evidence for the presence of the ascorbate-glutathione cycle in mitochondria and peroxisomes of pea leaves. Plant Physiol. 114, 275-284.

Jubany-Mari, T., Alegre-Batlle, L., Jiang, K., and Feldman, L. J. (2010). Use of a redox-sensing GFP (c-roGFP1) for real-time monitoring of cytosol redox status in Arabidopsis thaliana water-stressed plants. FEBS Lett. 584, 889-897. doi: 10.1016/j.febslet.2010.01.014

Kataya, A. M. R., and Reumann, S. (2010). Arabidopsis glutathione reductase 1 is dually targeted to peroxisomes and the cytosol. Plant Signal Behav. 5, 171-175. doi: $10.4161 /$ psb.5.2.10527

Kwon, E., Feechan, A., Yun, B.-W., Hwang, B.-H., Pallas, J. A., Kang, G.-J., et al. (2012). AtGSNOR1 function is required for multiple developmental programs in Arabidopsis. Planta 236, 887-900. doi: 10.1007/s00425-0121697-8

Laloi, C., Stachowiak, M., Pers-Kamczyc, E., Warzych, E., Murgia, I., and Apel, K. (2007). Cross-talk between singlet oxygen- and hydrogen peroxide-dependent signaling of stress responses in Arabidopsis thaliana. Proc. Natl. Acad. Sci. U.S.A. 104, 672-677. doi: 10.1073/pnas.0609063103

Lu, Y. P., Li, Z. S., Drozdowicz, Y. M., Hörtensteiner, S., Martinoia, E., and Rea, P. A. (1998). AtMRP2, an Arabidopsis ATP binding cassette transporter able to transport glutathione $S$-conjugates and chlorophyll catabolites: functional comparisons with AtMRP1. Plant Cell 10, 267-282.

Mannervik, B. (1985). Glutathione peroxidases. Meths. Enzymol. 113, 490-495. doi: 10.1016/S0076-6879(85)13063-6 
Martinoia, E., Grill, E., Tommasini, R., Kreuz, K., and Amrhein, N. (1993). ATPdependent glutathione $S$-conjugate 'export' pump in the vacuolar membrane of plants. Nature 364, 247-249. doi: 10.1038/364247a0

Marty, L., Siala, W., Schwarzländer, M., Fricker, M. D., Wirtz, M., Sweetlove, L. J., et al. (2009). The NADPH-dependent thioredoxin system constitutes a functional backup for cytosolic glutathione reductase in Arabidopsis. Proc. Natl. Acad. Sci. U.S.A.106, 9109-9114. doi: 10.1073/pnas.0900206106

Meyer, A. J. (2008). The integration of glutathione homeostasis and redox signaling. J. Plant Physiol. 165, 1390-1403. doi: 10.1016/j.jplph.2007.10.015

Meyer, A. J., Brach, T., Marty, L., Kreye, S., Rouhier, N., Jacquot, J. P., et al. (2007). Redox-sensitive GFP in Arabidopsis thaliana is a quantitative biosensor for the redox potential of the cellular glutathione redox buffer. Plant J. 52, 973-986. doi: 10.1111/j.1365-313X.2007.03280.x

Mhamdi, A., Queval, G., Chaouch, S., Vanderauwera, S., Van Breusegem, F., and Noctor, G. (2010a). Catalase in plants: a focus on Arabidopsis mutants as stressmimic models. J. Exp. Bot. 61, 4197-4220. doi: 10.1093/jxb/erq282

Mhamdi, A., Hager, J., Chaouch, S., Queval, G., Han, Y., Taconnat, L., et al. (2010b). Arabidopsis GLUTATHIONE REDUCTASE 1 plays a crucial role in leaf responses to intracellular $\mathrm{H}_{2} \mathrm{O}_{2}$ and in ensuring appropriate gene expression through both salicylic acid and jasmonic acid signaling pathways. Plant Physiol. 153, 1144-1160. doi: 10.1104/pp.110.153767

Michelet, L., Zaffagnini, M., Marchand, C., Collin, V., Decottignies, P., Tsan, P., et al. (2005). Glutathionylation of chloroplast thioredoxin $\mathrm{f}$ is a redox signaling mechanism in plants. Proc. Natl. Acad. Sci. U.S.A. 102, 16478-16483. doi: 10.1073/pnas.0507498102

Nakano, Y., and Asada, K. (1987). Purification of ascorbate peroxidase in spinach chloroplasts: its inactivation in ascorbate-depleted medium and reactivation by monodehydroascorbate radical. Plant Cell Physiol. 28, 131-140.

Navrot, N., Collin, V., Gualberto, J., Gelhaye, E., Hirasawa, M., Rey, P., et al. (2006) Plant glutathione peroxidases are functional peroxiredoxins distributed in several subcellular compartments and regulated during biotic and abiotic stress. Plant Physiol. 142, 1364-1379. doi: 10.1104/pp.106.089458

Nishizawa, A., Yabuta, Y., and Shigeoka, S. (2008). Galactinol and raffinose constitute a novel function to protect plants from oxidative damage. Plant Physiol. 147, 1251-1263. doi: 10.1104/pp.108.122465

Noctor, G., Mhamdi, A., Queval, G., and Foyer, C. H. (2013). Regulating the redox gatekeeper: vacuolar sequestration puts glutathione disulfide in its place. Plant Physiol. 163, 665-671. doi: 10.1104/pp.113.223545

Nutricati, E., Miceli, A., Blando, F., and De Bellis, L. (2006). Characterization of two Arabidopsis thaliana glutathione S-transferases. Plant Cell Rep. 25, 997-2005. doi: 10.1007/s00299-006-0146-1

Park, H. J., Cho, H.Y., and Kong, K. H. (2005). Purification and biochemical properties of glutathione S-transferase from Lactuca sativa. J. Biochem. Mol. Biol. 38 232-237. doi: 10.5483/BMBRep.2005.38.2.232

Polle, A. (2001). Dissecting the superoxide dismutase-ascorbate-glutathione- pathway in chloroplasts by metabolic modeling: computer simulations as a step towards flux analysis. Plant Physiol. 126, 445-462. doi: 10.1104/pp.126.1.445

Pulido, P., Spínola, M. C., Kirchsteiger, K., Guinea, M., Pascual, M. B., Sahrawy, M., et al. (2010). Functional analysis of the pathways for 2-Cys peroxiredoxin reduction in Arabidopsis thaliana chloroplasts. J. Exp. Bot. 61, 4043-4054. doi: $10.1093 /$ jxb/erq218

Queval, G., Jaillard, D., Zechmann, B., and Noctor, G. (2011). Increased intracellular $\mathrm{H}_{2} \mathrm{O}_{2}$ availability preferentially drives glutathione accumulation in vacuoles and chloroplasts. Plant Cell Environ. 34, 21-32. doi: 10.1111/j.13653040.2010.02222.x

Queval, G., Neukermans, J., Vanderauwera, S., Van Breusegem, F., and Noctor, G. (2012). Day length is a key regulator of transcriptomic responses to both $\mathrm{CO}_{2}$ and $\mathrm{H}_{2} \mathrm{O}_{2}$ in Arabidopsis. Plant Cell Environ. 35, 374-387. doi: 10.1111/j.13653040.2011.02368.x

Queval, G., Thominet, D., Vanacker, H., Miginiac-Maslow, M., Gakière, B., and Noctor, G. (2009). $\mathrm{H}_{2} \mathrm{O}_{2}$-activated up-regulation of glutathione in Arabidopsis involves induction of genes encoding enzymes involved in cysteine synthesis in the chloroplast. Mol. Plant 2, 344-356. doi: 10.1093/mp/ssp002

Riondet, C., Desouris, J. P., Montoya, J. G., Chartier, Y., Meyer, Y., and Reichheld, J. P. (2012). A dicotyledon-specific glutaredoxin GRXC1 family with dimerdependent redox regulation is functionally redundant with GRXC2. Plant Cell Environ. 35, 360-373. doi: 10.1111/j.1365-3040.2011.02355.x

Rizhsky, L., Hallak-Herr, E., Van Breusegem, F., Rachmilevitch, S., Barr, J. E., Rodermel, S., et al. (2002). Double antisense plants lacking ascorbate peroxidase and catalase are less sensitive to oxidative stress than single antisense plants lacking ascorbate peroxidase or catalase. Plant J. 32, 329-342. doi: 10.1046/j.1365313X.2002.01427.x

Rouhier, N. (2010). Plant glutaredoxins: pivotal players in redox biology and iron-sulphur centre assembly. New Phytol. 186, 365-372. doi: 10.1111/j.14698137.2009.03146.x

Rouhier, N., Gelhaye, E., and Jacquot, J. P. (2004a). Plant glutaredoxins: still mysterious reducing systems. Cell Mol. Life Sci. 61, 1266-1277. doi: 10.1007/s00018004-3410-y

Rouhier, N., Gelhaye, E., Corbier, C., and Jacquot, J. P. (2004b). Active site mutagenesis and phospholipid hydroperoxide reductase activity of poplar type II peroxiredoxin. Physiol. Plant. 120, 57-62. doi: 10.1111/j.0031-9317. 2004.0203.x

Rouhier, N., Gelhaye, E., and Jacquot, J. P. (2002). Glutaredoxin-dependent peroxiredoxin from poplar: protein-protein interaction and catalytic mechanism. J. Biol. Chem. 277, 13609-13614. doi: 10.1074/jbc.M111489200

Rouhier, N., and Jacquot, J. P. (2005). The plant multigenic family of thiol peroxidases. Free Radic. Biol. Med. 38, 1413-1421. doi: 10.1016/j.freeradbiomed.2004.07.037

Rouhier, N., Villarejo, A., Srivastava, M., Gelhaye, E., Keech, O., Droux, M., et al. (2005). Identification of plant glutaredoxin targets. Antioxid. Redox Signal. 7, 919-929. doi: 10.1089/ars.2005.7.919

Roxas, V. P., Lodhi, S. A., Garrett, D. K., Mahan, J. R., and Allen, R. D. (2000). Stress tolerance in transgenic tobacco seedlings that overexpress glutathione S-transferase/glutathione peroxidase. Plant Cell Physiol. 41, 1229-1234. doi: $10.1093 / \mathrm{pcp} / \mathrm{pcd} 051$

Sakamoto, A., Ueda, M., and Morikawa, H. (2002). Arabidopsis glutathionedependent formaldehyde dehydrogenase is an $S$-nitrosoglutathione reductase. FEBS Lett. 515, 20-24. doi: 10.1016/S0014-5793(02)02414-6

Schwarzländer, M., Fricker, M. D., Müller, C., Marty, L., Brach, T., Novak, J., et al (2008). Confocal imaging of glutathione redox potential in living plant cells. J. Microsc. 231, 299-316. doi: 10.1111/j.1365-2818.2008.02030.x

Sen Gupta, A., Alscher, R. G., and McCune, D. (1991). Response of photosynthesis and cellular antioxidants to ozone in Populus leaves. Plant Physiol. 96, 650-655. doi: 10.1104/pp.96.2.650

Sen Gupta, A., Webb, R. P., Holaday, S., and Allen, R. (1993). Overexpression of superoxide dismutase protects plants from oxidative stress. Induction of ascorbate peroxidase in superoxide dismutase-overexpressing plants. Plant Physiol. 103, 1067-1073.

Shimaoka, T., Miyake, C., and Yokota, A. (2003). Mechanism of the reaction catalyzed by dehydroascorbate reductase from spinach chloroplasts. Eur. J Biochem. 270, 921-928. doi: 10.1046/j.1432-1033.2003.03452.x

Shimaoka, T., Yokota, A., and Miyake, C. (2000). Purification and characterization of chloroplast dehydroascorbate reductase fom spinach leaves. Plant Cell Physiol. 41, 1110-1118. doi: 10.1093/pcp/pcd035

Smith, I. K., Kendall, A. C., Keys, A. J., Turner, J. C., and Lea, P. J. (1985). The regulation of the biosynthesis of glutathione in leaves of barley (Hordeum vulgare L.). Plant Sci. 41, 11-17. doi: 10.1016/0168-9452(85)90059-7

Su, T., Xu, J., Li, Y., Lei, L., Zhao, L., Yang, H., et al. (2011). Glutathione-indole-3acetonitrile is required for camalexin biosynthesis in Arabidopsis thaliana. Plant Cell 23, 364-380. doi: 10.1105/tpc.110.079145

Tang, Z. X., and Yang, H. L. (2013). Functional divergence and catalytic properties of dehydroascorbate reductase family proteins from Populus tomentosa. Mol. Biol. Rep. 40, 5105-5114. doi: 10.1007/s11033-11013-2612-5

Tarrago, L., Laugier, E., Zaffagnini, M., Marchand, C., Le Maréchal, P., Rouhier, N., et al. (2009). Regeneration mechanisms of Arabidopsis thaliana methionine sulfoxide reductases B by glutaredoxins and thioredoxins. J. Biol. Chem. 284, 18963-18971. doi: 10.1074/jbc.M109.015487

Tripathi, B. N., Bhatt, I., and Dietz, K. J. (2009). Peroxiredoxins: a less studied component of hydrogen peroxide detoxification in photosynthetic organisms. Protoplasma 235, 3-15. doi: 10.1007/s00709-009-0032-0

Urano, J., Nakagawa, T., Maki, Y., Masumura, T., Tanaka, K., Murata, N., et al. (2000). Molecular cloning and characterization of a rice dehydroascorbate reductase. FEBS Lett. 466, 107-111. doi: 10.1016/S0014-5793(99) 01768-8

Vanacker, H., Carver, T. L. W., and Foyer, C. H. (2000). Early $\mathrm{H}_{2} \mathrm{O}_{2}$ accumulation in mesophyll cells leads to induction of glutathione during the hypersensitive response in the barley-powdery mildew interaction. Plant Physiol. 123, 1289-1300. doi: 10.1104/pp.123.4.1289 
Wagner, U., Edwards, R., Dixon, D. P., and Mauch, F. (2002). Probing the diversity of the Arabidopsis glutathione S-transferase gene family. Plant Mol. Biol. 49, 515-532. doi: 10.1023/A:1015557300450

Wang, Z., Xiao, Y., Chen, W., Tang, K., and Zhang, L. (2010). Increased vitamin C content accompanied by an enhanced recycling pathway confers oxidative stress tolerance in Arabidopsis. J. Integr. Plant Biol. 52, 400-409. doi: 10.1111/j.17447909.2010.00921.x

Wells, W. W., Xu, D. P., Yang, Y., and Rocque, P. A. (1990). Mammalian thioltransferase (glutaredoxin) and protein disulfide isomerase have dehydroascorbate reductase activity. J. Biol. Chem. 265, 15361-15364.

Willekens, H., Chamnongpol, S., Davey, M., Schraudner, M., Langebartels, C., Van Montagu, M., et al. (1997). Catalase is a sink for H2O2 and is indispensable for stress defense in C3 plants. EMBO J. 16, 4806-4816. doi: 10.1093/emboj/16.16.4806

Winterbourn, C. C. (2013). The biological chemistry of hydrogen peroxide. Methods Enzymol. 528, 3-25. doi: 10.1016/B978-0-12-405881-1.00001-X

Yang, X., Sun, W., Liu, J. P., Liu, Y. J., and Zeng, Q. Y. (2009). Biochemical and physiological characterization of a tau class glutathione transferase from rice (Oryza sativa). Plant Physiol. Biochem. 47, 1061-1068. doi: 10.1016/j.plaphy.2009.07.003

Yin, L., Wang, S., Eltayeb, A. E., Uddin, M. I., Yamamoto, Y., Tsuji, W., et al. (2010). Overexpression of dehydroascorbate reductase, but not monodehydroascorbate reductase, confers tolerance to aluminum stress in transgenic tobacco. Planta 231, 609-621. doi: 10.1007/s00425-009-1075-3
Yoshida, S., Tamaoki, M., Shikano, T., Nakajima, N., Ogawa, D., Ioki, M., et al. (2006). Cytosolic dehydroascorbate reductase is important for ozone tolerance in Arabidopsis thaliana. Plant Cell Physiol. 47, 304-308. doi: 10.1093/pcp/pci246 Zaffagnini, M., Bedhomme, M., Lemaire, S. D., and Trost, P. (2012). The emerging roles of protein glutathionylation in chloroplasts. Plant Sci. 185-186, 86-96. doi: 10.1016/j.plantsci.2012.01.005

Conflict of Interest Statement: The authors declare that the research was conducted in the absence of any commercial or financial relationships that could be construed as a potential conflict of interest.

Received: 20 September 2013; paper pending published: 30 October 2013; accepted: 04 November 2013; published online: 25 November 2013.

Citation: Rahantaniaina M-S, Tuzet A, Mhamdi A and Noctor G (2013) Missing links in understanding redox signaling via thiol/disulfide modulation: how is glutathione oxidized in plants? Front. Plant Sci. 4:477. doi: 10.3389/fpls.2013.00477

This article was submitted to Plant Physiology, a section of the journal Frontiers in Plant Science.

Copyright (c) 2013 Rahantaniaina, Tuzet, Mhamdi and Noctor. This is an openaccess article distributed under the terms of the Creative Commons Attribution License (CC BY). The use, distribution or reproduction in other forums is permitted, provided the original author(s) or licensor are credited and that the original publication in this journal is cited, in accordance with accepted academic practice. No use, distribution or reproduction is permitted which does not comply with these terms. 